\title{
OFICINAS EXPRESSIVAS: UMA INCLUSÃO DE SINGULARIDADES
}

\author{
Flávia Helena Passos Pádua
}

Maria de Lima Salum e Morais

Resumo: Este artigo pretende fazer uma reflexão crítica sobre as atividades artísticas realizadas nos serviços de saúde mental e nos diversos espaços sociais. Inicialmente, contextualiza-se como a loucura tem sido percebida socialmente, como o trabalho tem sido visto na forma de tratamento moral e como a assistência psiquiátrica modificou-se no decorrer da história. A seguir, problematizam-se as formas ainda exclusoras de realizar oficinas terapêuticas apenas em serviços de saúde mental e unicamente com a participação de pessoas que possuem transtornos mentais. Questiona-se também a clínica tradicional e cronificante. Discute-se, ainda, a segregação daqueles que desviam da serialização de subjetividades impostas pela sociedade de controle. As atividades expressivas propõem a inclusão de múltiplas singularidades. Além disso, busca-se um acolhimento às diversas formas de linguagem, não apenas aquelas restritas ao verbal, e a circulação de afetos e de produções artísticas em diversos territórios comunitários.

Palavras-chave: Saúde mental. Experimentações artísticas. Produção de subjetividades. Inserção social.

Para que então existo?

Pergunto assim com espanto,

Se minha voz e meu grito

Ninguém sequer ousa ouvir

Só vivo triste a pensar,

Pois esse triste pranto

Ninguém escuta eu chorar

Se digo qualquer coisa à toa

Ninguém escuta o que eu digo

Quando meu grito entoa 
No espaço fica perdido

Falam até que eu sou louco

Eque no mundo não sou ninguém

De mim até fazem pouco

E me tratam com desdém

Mas se pararem um pouco

E me prestarem atenção

Verão que não sou nada louco

E tenho bom coração.

Posso até ser diferente

Com meu jeito der ser

Mas ficaria contente,

Se me deixassem viver.

José Ivan de Lima - passou por internações psiquiátricas, é compositor de músicas, poeta e artesão.

\section{Breve Histórico Da Assistência Psiquiátrica}

Durante a Idade Média, na Europa, as cidades expulsavam os loucos de seus muros. Segundo Foucault (1995), "acontecia de alguns loucos serem chicoteados publicamente, e que no decorrer de uma espécie de jogo eles fossem a seguir perseguidos numa corrida simulada e escorraçados da cidade a bastonadas" (p. 11). Geralmente, isso ocorria com estrangeiros, já que havia hospitais e leitos para os loucos moradores da região.

Para que os insanos fossem embora das cidades, os marinheiros os levavam para portos distantes, para que lá fossem abandonados. Era essa a Nau dos Loucos, estranho barco simbólico em busca da razão, o qual assegurava que os insensatos permanecessem prisioneiros de sua própria partida (Foucault, 1995). Assim, esses sujeitos eram rejeitados onde fossem e não tinham a possibilidade de vivenciar sua singularidade.

No século XVII,os pobres, os vagabundos, os criminosos, as prostitutas, os doentes, os loucos eram enclausurados em asilos, o que Foucault (1995) chamou de o "grande internamento". Nessa época, a loucura ainda estava separada do saber médico e a exclusão dos insanos estava ligada muito mais à ordem do que à doença. Segundo Guerra (2004), nesse período, o asilo "era uma instância da ordem monárquica, de cunho social, inserida na política da assistência, substituindo a ação religiosa, não se constituindo, pois, num aparato médico, mas antes, num dispositivo social" (p. 26). 
Havia uma preocupação em isolar todos aqueles que pudessem causar desordem social, já que a mendicância e a improdutividade eram condenadas pela burguesia desse período (Cedraz \& Dimenstein, 2005). Por isso, mesmo dentro desses asilos, procurava-se evitar que os internos ficassem ociosos e obrigavam-nos a fazer trabalhos como tecer, polir e até substituir os cavalos na moinha. Ainda não havia nenhuma intenção terapêutica nessas atividades; elas eram apenas uma forma de controle social, uma solução para o pecado do ócio (Guerra, 2004).

No final do século XVIII, o enclausuramento - uma marca do absolutismo - tinha que ser abolido, pois os ideais da Revolução Francesa eram "Liberdade, Igualdade, Fraternidade."Porém, ainda se considerava necessário segregar o louco para manter a ordem, o que foi possível com as ideias de cientificidade e valorização da razão advindas do lluminismo. A partir desse momento, a loucura passa a ser objeto de estudo da psiquiatria, a qual visa a isolar os "doentes mentais" para que sejam observados em seu estado mais puro. Estava, assim, institucionalizada a loucura delimitada pelo saber/poder médico (Amarante, 1995; Cedraz \& Dimenstein, 2005).

Começa-se a crer em uma possibilidade de cura do organismo que sofre de uma disfunção fisiológica, uma alteração bioquímica do cérebro. Com isso, "a dimensão de sujeito é simplesmente substituída pela de organismo" (Corbisier, 2000, p. 286). Portanto, não se via o indivíduo, a sua experiência singular, e, sim, um corpo doente que precisava ser tratado e medicalizado.

Tendo em vista que também se pensava o louco como portador de uma razão não absoluta e contraditória, esse era considerado "alienado, incapaz de julgar, de escolher, incapaz mesmo de ser livre e cidadão, pois a liberdade e a cidadania implicavam no direito e possibilidade à escolha" (Amarante, 2003, p.51). Por isso, buscava-se, através do isolamento e do tratamento moral, restituir razão aos doentes mentais para se readaptarem à sociedade capitalista e serem sujeitos úteis, capazes de produzir e consumir. Basaglia (1985) afirma que, no sistema capitalista,"tudo aquilo que não produz é doente" (p.46).

Philippe Pinel, um médico francês, diretor do asilo Bicêtre, foi um dos precursores do tratamento moral. Ele reorganizou o espaço hospitalar através da separação e classificação das "espécies de doentes mentais".Para ele, não importava a origem da doença no organismo, mas, sim, uma observação empírica, descritiva, com vigilância constante e registro contínuo dos sintomas a partir da nosografia (Guerra, 2004). Como forma de tratamento, utilizava-se também o trabalho. Contudo, não eram atividades que visavam à autonomia dos sujeitos, mas um trabalho monótono que pudesse mantê-los entretidos, alienados - uma forma de dominar seus impulsos e de adestrá-los. Essas atividades, além de mantê-los ocupados, tinham o objetivo de manter o funcionamento dos hospitais com a mão de obra não 
remunerada dos internos (Valladares, Lappann-Botti, Mello, Kantorski \& Scatena, 2003).

Outra função desses trabalhos era uma reeducação moral para que os enclausurados se reajustassem às regras sociais. Assim, aprisionava-se, além do corpo, a subjetividade e a capacidade criativa desses indivíduos. Enfim, era uma restrição do campo existencial, uma forma de repressão através da disciplina (Cedraz \& Dimenstein, 2005).

Essa forma de tratamento, baseada no treinamento e na obediência, era também uma forma de punição, já que, no imaginário social, influenciado pela psiquiatria, havia uma intrínseca relação entre loucura e periculosidade. Amarante (2003) afirma que, nesse período,"o manicômio torna-se a expressão deste modelo que se calca na tutela, na vigilância panóptica, no tratamento moral, na disciplina, na imposição da ordem, na punição corretiva, no trabalho terapêutico, na custódia e interdição" (p. 51). Portanto, o modelo assistencial psiquiátrico estava ligado ao campo jurídico-político e considerava o doente mental como irracional, sem responsabilidade civil e incapaz de estabelecer trocas sociais e simbólicas (Amarante, 2003). Assim, através do trabalho alienado, da excessiva medicalização e de um tratamento baseado em uma relação hierárquica vertical, em que o médico era o profissional central, mantinha-se a ordem, a tranquilidade e os loucos não incomodavam a sociedade.

No entanto, no período Pós-Guerra, houve superlotação de internos, havia uma pequena quantidade de funcionários nos hospitais psiquiátricos e percebeu-se a ineficiência das propostas de tratamento existentes, que não recuperavam os pacientes (Amarante, 1995). Eram necessárias, então, novas formas de tratamento para reabilitar essa grande mão de obra perdida e, a partir disso, reestruturar os países abalados pela guerra.

Exemplos dessas tentativas de reformas do modelo psiquiátrico são as Comunidades Terapêuticas surgidas na Inglaterra, a Psicoterapia Institucional e a Psiquiatria de Setor propostas na França e a Psiquiatria Preventiva originada nos EUA, que ocorreram concomitantemente na segunda metade do século XX. Nas duas primeiras, pretendia-se apenas modificar o funcionamento do espaço asilar para que esse não fosse cronificante e tornar o ambiente terapêutico. Porém, em ambas as psiquiatrias reformadas, não havia uma reflexão de como os internos poderiam inserir-se na sociedade, salientado, assim, a segregação desses indivíduos. Já na Psiquiatria de Setor e na Psiquiatria Preventiva, buscava-se que os pacientes interagissem com a comunidade, mas não houve mudanças na concepção da loucura, ou seja, foi apenas uma "extensão da psiquiatria ao espaço público" (Amarante, 1995, p. 22). De acordo com Rauter (2000), “a adaptação pura e simples do doente mental à sociedade é o horizonte da maioria dessas reformas pelas quais passou a psiquiatria" (p. 267).

Guerra (2004) também afirma que os movimentos reestruturantes da psiquiatria ainda se preocupavam em reeducar socialmente os doentes 
mentais e em recuperar a mão de obra através de um trabalho alienado; o médico ainda era o centro do saber/poder e a forma de tratamento era de acordo com a patologia apresentada, não se refletindo, portanto, sobre a singularidade do sujeito.

Essa reflexão ocorre apenas a partir da Reforma Democrática Italiana, cujo precursor foi Franco Basaglia, que provocou uma mudança na concepção de loucura, passando a considerá-la como "crise vital" relacionada à subjetividade e não uma esquizofrenia, um diagnóstico, uma estereotipia que aprisiona a singularidade do sujeito (Basaglia, 1979).

Na década de 1960, Franco Basaglia inicia na Itália o movimento da reforma psiquiátrica no manicômio de Gorizia. Primeiramente, o psiquiatra adotou o modelo das comunidades terapêuticas para a humanização dos hospitais psiquiátricos. No entanto, percebeu que, com um trabalho realizado apenas nos manicômios, evidenciava-se a exclusão da loucura. Era necessário que a reforma ocorresse na comunidade, que houvesse uma transformação no modo de ver o sujeito que enlouquece não mais como doente, perigoso e que deve ser submetido à tutela - e sim como alguém que sofre e precisa ser incluído no social (Amarante, 1995).

Portanto, para Basaglia, era fundamental que ocorresse a reabilitação, que seria a integração do indivíduo com intenso sofrimento psíquico nos diferentes espaços da sociedade e a reestruturação de sua autonomia. Além disso, era necessária a desinstitucionalização e não apenas uma desospitalização, ou seja, era preciso reabilitar o contexto social, mudar o modo de ver a loucura. Era necessário o que Amarante (2003) chamou de "revolução",ao invés de uma simples reestruturação do modelo assistencial psiquiátrico.

Em 1971, Basaglia realiza em Trieste o processo de desmontagem do aparato manicomial. Isso foi feito de fora para dentro, ou seja, quando havia uma discussão sobre dar alta a um paciente, por exemplo, ao invés de apenas os médicos tomarem essa decisão, a comunidade também participava das reuniões. Dessa forma, os moradores da comunidade percebiam que as necessidades dos loucos eram as mesmas deles: dinheiro, casa e família. Começa, então, a ocorrer uma identificação dos cidadãos com os internos e o início da integração daqueles que possuem transtornos mentais (Basaglia, 1979).

Nessa época, são construídos centros de saúde mental em cada área da cidade com 20 a 40 mil habitantes, funcionando 24 horas por dia, sete dias por semana. São abertos também vários grupos-apartamentos, que são residências onde moram usuários, além de cooperativas de trabalho e de um Serviço de Emergência Psiquiátrica. Em um período de 10 anos, o circuito manicomial de Trieste foi extinto e, em 1975, já havia sete Centros de Saúde Mental (Goldberg, 1992).

Goldberg (1992) afirma que, nas cooperativas, pretendia-se realizar um trabalho terapêutico com um compromisso social do paciente e de- 
senvolver atividades nas quais ele pudesse ocupar espaços cada vez mais heterogêneos. Nesses serviços, não havia apenas usuários de saúde mental, mas qualquer cidadão que quisesse participar. Com isso, as cooperativas se tornaram mais ricas do ponto de vista de trocas sociais. Havia, também, ateliês como os de dança, artes plásticas, argila, teatro e outros.

A partir desse movimento, buscava-se atenuar as relações baseadas no saber/poder médico e obter-se uma relação horizontal e não hierárquica entre os profissionais de saúde mental. $O$ tratamento passava a ser feito, então, por uma equipe multiprofissional integrada por enfermeiros, médicos, psicólogos, assistentes sociais e voluntários encarregados de atividades como as de acompanhantes terapêuticos. Essa equipe passou a fazer reuniões diárias para discutir os casos dos pacientes e os problemas institucionais, havendo, ainda, reuniões com a participação dos usuários (Goldberg, 1992).

Essa é a proposta do movimento da Psiquiatria Democrática Italiana, que se constitui em um "circuito de atenção que, ao mesmo tempo em que oferece e produz cuidados, oferece e produz novas formas de sociabilidade e de subjetividade para aqueles que necessitam de assistência psiquiátrica" (Amarante, 1995, p. 54).

\section{A Reforma Psiquiátrica No Brasil}

A reforma psiquiátrica brasileira se baseou no movimento italiano. O início da reforma no Brasil ocorreu no final da década de 1970, quando houve o movimento da redemocratização do país. Com a crescente contratação de leitos privados em hospitais que visavam ao lucro, com a crise institucional e financeira da previdência social e por a saúde pública ser, nessa época, essencialmente assistencialista, hospitalocêntrica e ineficiente, era evidente a necessidade da reformulação da assistência à saúde no país.

Após muitas reivindicações para mudanças desse falho sistema, em 1990, institui-se o SUS (Sistema Único de Saúde) através das leis federais 8.080 e 8.142. De acordo com essas leis, a saúde é um direito universal do ser humano e dever do Estado. Além disso, consta nas mesmas o princípio de integralidade do indivíduo - que não deve ser visto como um "amontoado" de partes - e dos diversos níveis de assistência para que se constitua uma rede de atenção voltada para a proteção, promoção e recuperação da saúde individual e coletiva. A participação da comunidade, a equidade, a preservação da autonomia do sujeito, a descentralização dos recursos e as transferências intergovernamentais de recursos financeiros também são importantes princípios e diretrizes contidas nessas leis.

Através da reformulação da assistência à saúde, a reforma psiquiátrica foi fomentada com a proposta do projeto de lei no 3.657 de 1989, de autoria do deputado federal Paulo Delgado. Esse deputado visava "a desinstitucionalização da loucura e a construção de uma sociedade sem ma- 
nicômios, além da desospitalização progressiva da assistência psiquiátrica" (Guerra, 2004, p. 37).

Segundo Cedraz e Dimenstein (2005), em 1997, esse projeto foi rejeitado pela Comissão de Assuntos Sociais do Senado, já que se considerava a internação psiquiátrica eficiente para o tratamento de usuários de saúde mental quando os recursos extra-hospitalares não conseguissem superar as crises. Assim, diferentemente de Trieste, a internação em hospitais psiquiátricos continuou a ser constante no país. De acordo com o Documento Reforma psiquiátrica e política de saúde mental no Brasil (Brasil, 2005), apresentado na "Conferência Regional de Reforma dos Serviços de Saúde Mental: 15 anos depois de Caracas", ainda havia, em 2005, 42.078 leitos psiquiátricos no Brasil.

Apesar disso, o projeto de lei Paulo Delgado favoreceu a criação de oito leis estaduais que reorientavam o modelo de atenção na década de 1990 e deu origem à lei $n^{\circ} 10.216$ de 2001. Segundo essa lei, o tratamento às pessoas com transtornos mentais tem como finalidade permanente $a$ reinserção social do paciente em seu meio, o local do tratamento deve ser preferencialmente em serviços comunitários de saúde mental e "o regime de internação será estruturado de forma a oferecer assistência integral à pessoa portadora de transtornos mentais, incluindo serviços médicos, de assistência social, psicológicos, ocupacionais, de lazer e outros" (§ $2^{\circ}$ - Brasil, 2001).

A partir da reforma psiquiátrica e da regulamentação de leis e portarias, a atenção à saúde mental passou a ser organizada como uma rede de cuidados psicossociais dirigida a pessoas com transtornos mentais e constituída por ações de saúde mental na atenção básica, serviços residenciais terapêuticos, leitos em hospitais gerais, Centros de Convivência, Programa de Volta para Casa e CAPSs (Centro de Atenção Psicossocial). Os CAPSs possuem a função estratégica de organizar essa rede e de articular-se com outras redes, como as sociossanitárias, jurídicas, cooperativas de trabalho, escolas e empresas que possam promover a vida comunitária e a autonomia dos usuários (Brasil, 2004).

Os CAPSs podem ser de diversos tipos: CAPS I - em municípios com população entre 20.000 e 70.000 habitantes, que funcionam das 8 às 18 horas, de segunda a sexta-feira; CAPS II - em municípios com população entre 70.000 e 200.000 habitantes, que funcionam das 8 às 18 horas, de segunda a sexta-feira; CAPS III - em municípios com população acima de 200.000 habitantes, que funcionam 24 horas, inclusive nos feriados e finais de semana; CAPSi - para infância e adolescência em municípios com população acima de 200.000 habitantes, funcionando das 8 às 18 horas, de segunda a sexta-feira; CAPSad - para usuários de álcool e drogas em municípios com população acima de 200.000 habitantes, funcionando das 8 às 18 horas, de segunda a sexta-feira (Brasil, 2004). 
Nos CAPSs, há equipes multiprofissionais que geralmente são formadas por médicos, enfermeiros, técnicos e/ou auxiliares de enfermagem, técnicos administrativos, técnicos educacionais, artesãos, psicólogos, assistentes sociais, terapeutas ocupacionais, pedagogos ou outros profissionais necessários ao projeto terapêutico.

\section{As Oficinas Terapêuticas}

As oficinas terapêuticas foram regulamentadas pela portaria $n^{\circ} 189$ em 1991. Segundo essa portaria, as oficinas são atividades grupais realizadas geralmente em serviços extra-hospitalares (embora alguns hospitais também utilizem esse procedimento) e possuem função de socialização, expressão e inserção social (Brasil, 1991). São coordenadas por um ou mais profissionais e têm a finalidade de "maior integração social e familiar, a manifestação de sentimentos e problemas, o desenvolvimento de habilidades corporais, a realização de atividades produtivas e o exercício coletivo da cidadania" (Brasil, 2004, p. 20).

As oficinas, diferentemente do que ocorria nos manicômios, não são práticas impostas àqueles que possuem transtornos mentais. São propostas de acordo com o projeto terapêutico formulado pela equipe terapêutica e é o usuário quem decide se as oficinas Ihe interessam ou não.

Uma das principais ferramentas dos procedimentos terapêuticos é a escuta, também utilizada nas oficinas. Com a escuta, é possível perceber o significado da experiência do sofrimento para a pessoa que fala naquele momento, naquele contexto (Corbisier, 2000). Assim, ao invés de encaixar o sujeito que sofre em uma patologia, propõe-se que, através da escuta, haja a possibilidade de o indivíduo compartilhar suas experiências e sentimentos e de perceber suas idiossincrasias.

Há diversas modalidades de oficinas terapêuticas: oficinas expressivas, oficinas geradoras de renda e oficinas de alfabetização. As oficinas expressivas são espaços em que os usuários trabalham com a expressão plástica, como a pintura, por exemplo; a expressão corporal, como a dança; a expressão verbal, com poesias, contos etc.; a expressão musical; a fotografia; e o teatro. As oficinas geradoras de renda são para o sustento ou para complementação da renda daqueles que possuem intenso sofrimento psíquico, através da aprendizagem de alguma atividade específica. Podem ser de culinária, marcenaria, artesanato em geral, fabricação de velas, vendas etc. Assim, essas oficinas são importantes formas de promoção de autonomia e de reinserção social do sujeito. As oficinas de alfabetização são para aqueles que não tiveram acesso à educação formal ou não continuaram os estudos aprenderem a escrita e a leitura e, dessa forma, (re)construírem sua cidadania (Brasil, 2004). No presente trabalho, priorizou-se a análise das oficinas expressivas. 
Como não há muitos trabalhos científicos sobre as oficinas expressivas e por considerar importante uma reflexão de como essas atividades podem ser ferramentas para a reinserção dos usuários de saúde mental na sociedade, para promover a desinstitucionalização e para a produção de novas subjetividades, são necessários estudos aprofundados a respeito do assunto. Pretende-se, então, com o presente trabalho, fazer uma reflexão seletiva, crítica e analítica sobre as oficinas terapêuticas expressivas realizadas nos serviços de saúde mental e nos diversos espaços comunitários do Brasil.

A análise baseou-se em nove artigos científicos, ${ }^{1}$ duas dissertações de mestrado e dez livros que discutem o tema apresentado. Os trabalhos foram pesquisados nos meses de agosto a novembro de 2007. Procurouse selecionar aqueles estudos que foram publicados no período de 2000 a 2007 e que tinham uma perspectiva pós-estruturalista, utilizando como referencial teórico a Esquizoanálise. ${ }^{2}$ Selecionaram-se também trabalhos nos quais havia uma crítica à psiquiatria tradicional e ao tratamento moral e que discutiam como as atividades terapêuticas poderiam incluir os usuários de saúde mental na sociedade e produzir novas formas de aqueles que possuem intenso sofrimento psíquico se relacionarem com o mundo.

O método utilizado foi qualitativo, destacando os principais conteúdos verificados na literatura analisada. Após a análise, os trabalhos foram categorizados, conforme o principal foco e as ideias que trazem para a reflexão a respeito das oficinas terapêuticas, em quatro dimensões: (1) multiplicidade de linguagens; (2) resistência à serialização de modos de subjetivação; (3) ruptura da clínica tradicional; (4) vivência de outros espaços.

Dentro das dimensões mencionadas, passou-se a destacar e comentar os conteúdos encontrados nos trabalhos a que se refere a presente reflexão.

\section{Multiplicidade de linguagens}

As atividades realizadas nas oficinas expressivas são intermediárias na construção de vínculos entre participante-oficineiro e participante-participante. Elas podem fazer com que a palavra circule e que o usuário compartilhe suas histórias, experiências e sentimentos que, até aquele momento, não tiveram a possibilidade de ser expressos, escutados e acolhidos.

A comunicação não precisa ser necessariamente através da linguagem verbal. Experimentações no campo da arte também permitem a expressão de vivências e de sensações singulares e tornam essas produções artísticas uma forma de linguagem. Segundo Lima (2004), é importante o coordenador da oficina "acolher os sons, as falas, as formas, os atos, tecen-

\footnotetext{
Os artigos pesquisados foram citados nas plataformas Google Acadêmico, SciELO e Lilacs.

Muito resumidamente, a Esquizoanálise é um pensamento filosófico baseado nas ideias de Gilles Deleuze e Félix Guattari.É dissidente da análise institucional e não se fundamenta em pressupostos deterministas. Um dos eixos temáticos dessa teoria e prática política é a subjetividade, a qual não é entendida como algo cristalizado, mas em constante transformação e sempre produzida nas relações.
} 
do-os na trama do ateliê" (p. 75). Portanto, as relações construídas nesses espaços possuem múltiplas formas de linguagem que necessitam de um olhar atento e comprometido.

Através da potência criadora, produz-se um transbordamento por outras vias e tem-se a possibilidade de experimentar linguagens como a visual, auditiva e corporal. De acordo com Valladares et al. (2003), as atividades desenvolvidas nas oficinas expressivas valorizam as vivências criativas, expressivas, imaginativas e incentivam a originalidade e a despsiquiatrização do usuário de saúde mental. Assim, diferentemente do tratamento moral que produzia modos de ser e estar no mundo cristalizados, a arte possibilita novas produções de subjetividade.

Mendonça (2005) comenta que "as atividades das oficinas em saúde mental passam a ser vistas como instrumento de enriquecimento dos sujeitos, de valorização de expressão, de descoberta e ampliação de possibilidades" (p. 3). Com essa "injeção de potência" nos sujeitos com intenso sofrimento psíquico, buscam-se linhas de fuga da lógica manicomial e uma clínica não escrava de palavras, que vence a mera linguagem comum (Rocha, 1997). Uma clínica que, diferentemente da psicanálise, que utilizou a linguagem representacional para construir um modelo lógico-científico, inclua outras formas de expressão (Rauter, 1997).

\section{Resistência à serialização de modos de subjetivação}

As oficinas expressivas são uma das ferramentas contra-hegemônicas que podem promover uma ruptura da exclusão daqueles que são considerados diferentes, com "comportamentos bizarros" em relação às subjetividades uniformizadas. Na sociedade contemporânea, existe um padrão, uma norma a ser seguida de como os indivíduos devem se relacionar e se comportar. Cedraz e Dimenstein (2005) afirmam que a "ordem capitalística funciona no sentido de promover agenciamentos subjetivos segundo formas padronizadas, serializadas e homogêneas bloqueando a produção de modos de subjetividades singulares e de outros desejos" (p. 309). Assim, a sociedade capitalista produz uma massificação na qual aquele que destoa, provavelmente, será marginalizado.

Essa adequação aos modelos de beleza, desempenho e eficiência exigidos pela sociedade contemporânea está cada vez mais impiedosa, não apenas para aqueles que possuem transtornos mentais, mas para todos (Corbisier, 2000). Portanto, a ideia de fragilidade, de doença mental apenas como algo individual, como muitos acreditam, deve ser desconsiderada, já que é nítida a influência do contexto social adoecedor no sofrimento psíquico de todos os que (sobre)vivem nessa sociedade. Nessa perspectiva, a antipsiquiatria, uma psiquiatria reformada que se iniciou na década de 1960, na Inglaterra, fazia uma reflexão sobre o enlouquecer dizendo que "a loucura está entre os homens e não dentro do homem" (Amarante, 1995, p.47). 
A antipsiquiatria propõe uma discussão interessante e divergente das demais psiquiatrias reformadas anteriores. Considera o louco como vítima da alienação geral tida como norma e como o que contesta a estrutura social."A loucura é um fato social, político e até mesmo uma experiência positiva de libertação" (Amarante, 1995, p. 47). Por isso, a psiquiatria tradicional pretendeu isolar o louco para que, assim, o restante da população não percebesse nitidamente esse desequilíbrio social.

No entanto, as tentativas de dominação das consideradas desadaptações sociais não são mais tão facilmente perceptíveis atualmente. Gilles Deleuze (1992, citado por Lancetti, 2006) denominou essa dominação que ocorre ao ar livre, não mais no hospício, mas em todo lugar, de sociedade de controle. Esta ultrapassa a sociedade disciplinar, a qual era ordenada em espaços-tempos, cujo modelo era a fábrica.

A mídia é um dos principais equipamentos de controle e de serialização de subjetividades. É ela um dos fatores que determina como devemos relacionar-nos, como devemos ser e viver, vestir-nos, sobre o que devemos pensar e, principalmente, quem devemos discriminar. É um dos meios em que mais se promove a alienação.

Coimbra (2001) comenta que a mídia contribui para a exacerbação dos valores e das virtudes da instantaneidade, da descartabilidade, dos ganhos a curto prazo e do empobrecimento dos acontecimentos. O consumismo exacerbado faz com que tudo acabe sendo muito transitório, com significados que se esvaziam rapidamente e que podem ser facilmente substituídos, já que se pôde ter uma satisfação instantânea e fugaz.Tal consumismo excessivo de bens materiais pode acarretar até o consumismo de relações afetivas em que as pessoas são descartáveis.

Coimbra (2001) também afirma que a mídia induz formas de pensar, agir e perceber maniqueístas, dicotômicas. Assim, com um pensamento binário em que há o bem e o mal, o vilão e o mocinho, o louco e o sensato, o perigoso e o amável, prevalecem as formas segregacionistas e discriminadoras de se relacionar e não uma multiplicidade de maneiras de ser e estar no mundo.

Esse controle intensificado pela mídia é um dos principais mecanismos para a sociedade de controle se manter e docilizar os corpos. Quase que imperceptivelmente, de forma suave e persuasiva, sem revolta possível, sem prisão, pois as grades, agora, são as telas televisivas (Coimbra, 2001).

Outra característica da sociedade capitalista é que os aspectos econômicos prevalecem sobre as relações interpessoais e tudo gira em torno do capital. O dinheiro possui maior valor que o amor, que as políticas implementadas pelos governos, que os aspectos ligados ao trabalho (Rauter, 2000). É frequente que o aspecto que mais interfere na escolha profissional de muitos jovens é o de qual formação irá proporcionar um maior retorno financeiro, e não uma satisfação pessoal. É comum também que, ao escoIher o parceiro amoroso, priorize-se que uma de suas qualidades seja ter 
uma conta bancária avantajada ou que, pelo menos, a pessoa se esforce e trabalhe freneticamente. Assim como também é constante a desistência do governo de projetos sociais de gasto elevado em favor de projetos de baixo custo, mas que não interferem na qualidade de vida da população.

Com isso, produz-se uma desertificação,

desertificação das relações amorosas e do sexo, esvaziamento do campo coletivo, produção de um número cada vez maior de excluídos, não apenas do mercado de trabalho, mas de um cotidiano, já que muitos modos de ser não se adéquam a um mundo em que se colocam em primeiro plano os aspectos ligados à produtividade técnico-econômica. (Rauter, 2000, p. 270)

Portanto, em uma sociedade em que as pessoas são o que têm, os usuários de saúde mental ficam em desvantagem, já que muitos deles se sentem impossibilitados de trabalhar e de viver em uma sociedade competitiva como essa. Os loucos pobres são marginalizados por, segundo Basaglia (1979), "não serem produtivos em uma sociedade que se baseia na produtividade" (p.46).

As oficinas expressivas podem ser uma resistência a essa lógica alienante. Ao contrário da sociedade capitalista, que propõe uma desvinculação de trabalho com prazer, busca-se que, através de experimentações artísticas escolhidas pelos participantes, haja uma identificação do sujeito no fazer e em um trabalho criativo e satisfatório. Pela conjugação de trabalho e prazer, procura-se uma ruptura com a espera sofrida pelos finais de semana.

Além disso, com a arte, há a possibilidade de se contrapor ao modo hegemônico de ser sujeito e de acolher as singularidades para que surjam "novos orifícios respiratórios" (Rocha, 1997, p. 138). Rocha (1997) também aponta

as artes como a via por excelência, mais rigorosa para desmontar as engrenagens e composições de forças, responsáveis por um mundo que exclui do seu convívio aqueles que pensam diferente, ou expressam-se por meio de outros signos, não se restringindo ao simbólico. (p. 139)

Assim, a arte é um importante instrumento de inclusão e de produção de novas subjetividades. O que se propõe nas oficinas expressivas, portanto, é a criação de novos mundos, outras formas de se experimentar o viver e não mais, como comentam Cedraz e Dimenstein (2005), reduzir o mundo à mesmice.

Segundo Fonseca (2005), as oficinas são espaços não manicomiais por possuírem a potência de vibrar corpos medicalizados, em estado de dormência, onde já nada mais parece subsistir. Dessa forma, busca-se que, com as vivências artísticas, os participantes percebam que eles possuem múltiplas possibilidades imaginativas e criadoras e que permitam trazer à 
tona expressões livres. Livres inclusive da simples adaptação a que se propunha o tratamento moral.

No entanto, apesar de um dos objetivos das atividades expressivas ser o tentar romper com a lógica manicomial, sabe-se que ainda há muitas oficinas realizadas nos serviços de saúde mental que buscam apenas tornar os usuários produtivos e úteis à sociedade. Assim procedendo, pretende-se um trabalho que dê freio à loucura e que contribua para a ordem e economia institucional (Mangia, 1997).

Oliveira (2006) comenta que no CAPS Luz do Sol e CAPS Artur Bispo do Rosário, no município de Aracaju (SE), as oficinas de teatro, dança, música e coral eram consideradas superiores às demais, sendo permitida a participação nas mesmas apenas dos usuários que se adaptassem a elas, e não de todos aqueles que desejassem participar dessas atividades. Nessas oficinas

as diferenças de gestos, a dessimetria de movimentos e a dissonância de sons não eram aceitas, pois mostrava o horror da diferença concebida como anormalidade. Tratava-se de normalizar tais usuários, harmonizando-os, mostrando para a sociedade que eles não eram tão loucos assim. (Oliveira, 2006, p. 67)

As outras oficinas, de artesanato, marcenaria e trabalho com argila eram atividades que possuíam um ritmo intenso e fabril de produção.

Oliveira (2006), ao fazer uma reflexão sobre sua experiência nessas instituições, afirma que as oficinas de saúde mental se dividem em três grupos: as que pretendem fabricar, em um curto período de tempo, grandes quantidades de produtos que serão facilmente vendíveis no mercado; as que procuram produzir artistas para o mercado das artes; e aquelas que não se preocupam com o produto gerado, nem tampouco com o valor de troca dos mesmos.

Rauter (1997) também chegou a discutir a ideia apresentada por Oliveira ao comentar que há sempre duas vertentes no trabalho com os psicóticos: uma que busca tornar os loucos adaptados e produtivos e outra que visa à intensificação da capacidade criadora, não importando se o resultado dessa produção é útil ou não.

Contudo, para que as atividades artísticas sejam uma ampliação de potencialidades singulares, elas não devem se restringir à simples construção de artefatos, pois, assim, se reitera a "velha servidão do objeto" (Varella, 1997, p. 121). E nem muito menos fazer com que o valor do produto se imponha ao valor do produtor (Fadista \& Araújo, 2004). E, sim, buscar que, através da arte, as manifestações singulares possam emergir sem preocupações com a estética do produto. Portanto, "o gesto artístico superior não se equivale a produzir belos quadros e músicas. Ele se refere à produção de uma bela vida, a uma estética da própria existência. A vida como obra de arte" (Fonseca, 2005, p. 109). 


\section{Uma ruptura da clínica tradicional}

Ao se refletir sobre o método psicanalítico e psiquiátrico de diagnosticar os sujeitos e enquadrá-los em uma síndrome, considerando-os apenas como um amontoado de sintomas, percebe-se a necessidade de outras formas de se trabalhar com pessoas que possuem um intenso sofrimento psíquico. Lancetti (2006) faz uma discussão a respeito desse tema, ao dizer que os psiquiatras e psicólogos que ficam atrás de sua escrivaninha, no consultório, exercendo sua capacidade classificatória e seu silêncio, terão uma experiência estéril, burocratizada, segmentarizada e repetitiva.

Esse autor propõe uma clínica peripatética, que seriam conversações e pensamentos que acontecem durante um passeio, fora do consultório, em movimento. Essas estratégias seriam para aquelas pessoas que não se adéquam aos recursos técnicos tradicionais, como os psicóticos. Uma clínica com "espírito de inovação" (Lancetti, 2006, p. 30).

As oficinas expressivas precisam se apoderar desse espírito de inovação da clínica peripatética para não produzir uma simples adaptação dos usuários de saúde mental aos protocolos clínicos tradicionais já existentes. Não são os pacientes que devem aceitar os modelos de tratamento propostos; os profissionais é que devem usar sua capacidade inventiva para construir maneiras de diminuir o sofrimento dos usuários. Como afirma Fonseca (2005), deve-se "converter o moribundo do sistema técnico-científico em outras possibilidades" (p. 104).

As atividades artísticas, como uma dessas outras possibilidades, não podem permanecer na mesmice, devem estar em constante processo de modificação, já que qualquer trabalho clínico que não propõe rupturas tende à cronificação. Segundo Mendonça (2005), "cada encontro é inusitado, e, no imprevisto, pode proporcionar aprendizagem, produção, intercâmbio, ampliação das relações e mergulho no universo cultural, permitindo ao sujeito escapar à imposição do que é massificado em sua rotina" (p. 6). Portanto, cada oficina deverá ser única, singular, provocadora de espontaneidades.

Essas atividades, ao serem produtoras de descontinuidades, buscam experimentações múltiplas e linhas de fuga do modelo terapêutico normatizador (Lima, 2004). Através de manifestações artísticas, possibilita-se que o sujeito não produza obras estereotipadas, que foram ensinadas desde a pré-escola, como casas, árvores e pessoas que devem ser desenhadas de determinada forma e que, inclusive, são consideradas produções adequadas nos testes psicológicos. Dessa forma, as oficinas não propõem uma única, mas infinitas possibilidades de experimentar a arte. Um mergulho no caos, onde se permite uma vivência libertária.

Assim, com a arte, há a possibilidade de uma clínica que rompa com a submissão à norma. Uma clínica que acolha e potencialize singularidades Segundo Rauter (1997), 
pensar a subjetividade contemporânea do ponto de vista da clínica, buscando alternativas para seus impasses, passa necessariamente por retomar problemáticas do campo da arte. Pois se a clínica aspira produzir mutações no campo da subjetividade, deve aproximar-se da arte, talvez deva mesmo tornarse arte. (p. 109)

Portanto, as oficinas expressivas possuem um potencial desruptivo em relação à clínica tradicional e pretendem tornar-se uma estratégia inovadora e criativa. Por mais que se considere a expressão"criativa" imprecisa, esta é justamente a sua vantagem, a de não poder ser enxugada em alguma formulação técnica, seja ela qual for (Bezerra, 2004).

Deve-se, contudo, ressaltar que, como valorização de singularidades, é necessário também considerar o significado que cada participante atribui à oficina. Há atividades que possuem o objetivo de serem expressivas, mas determinado usuário pode considerá-la de geração de renda. Ela pode assumir qualquer característica, mas deverá ser nomeada de acordo com o seu objetivo principal (Almeida, Moraes, Barroso, Barros \& Sampaio, 2004). $\mathrm{O}$ oficineiro deve se questionar o porquê de fazer cada atividade, mas precisa compreender o que cada participante busca com determinado trabaIho. Se há intencionalidade dos usuários de se desviar do que foi proposto inicialmente, não há como se insistir em um objetivo que não existe. Não basta nomear uma atividade de terapêutica e fazer com que os usuários permaneçam na mesmice (Almeida, et al., 2004).

\section{Vivenciando outros espaços}

Através da literatura pesquisada, percebeu-se que ainda há muitas oficinas que são realizadas apenas nos serviços de saúde mental, não havendo preocupação em fazer com que os considerados loucos ocupem outros espaços destinados à comunidade em geral, tais como galerias, praças, escolas etc. As atividades realizadas exclusivamente nos serviços de saúde mental possuem apenas uma "roupagem" de inovadoras, porém ratificam a exclusão daqueles que possuem transtornos mentais. Essa exclusão ocorre, pois, retirando os internos dos hospitais psiquiátricos e apenas transferindo-os para os CAPSs,; continuam isolando-os da sociedade. Assim procedendo, não se promove a desinstitucionalização dos usuários, e sim segragam-nos em outros espaços. Dessa forma, continuam sem os seus direitos de cidadãos e percorrem apenas o caminho casa-serviço de saúde mental, ao invés de circular em outros locais da cidade. Desse modo, em alguns CAPSs, perpetua-se a lógica manicomial, só que agora em outra instituição: os CAPS-manicômios.

Lancetti (2006) afirma que "a experiência da desconstrução manicomial nos ensinou a importância do dentro e do fora do estabelecimento, das bordas como espaço privilegiado de produção de subjetividade cidadã" (p.51). No entanto, ainda há muitos CAPSs centralizados em si mesmos, 
que não se preocupam em desbravar outros espaços da comunidade, nem em promover uma reinserção dos usuários de saúde mental na sociedade e nem em transformar o modo como a população considera aquele que possui intenso sofrimento psíquico. Há, portanto, duas formas de se trabalhar com saúde mental: (1) manter os usuários nas instituições de tratamento e perpetuar um movimento cristalizado; ou (2) estender a ação para o território, e, assim, buscar extinguir a discriminação e a exclusão do sujeito que vivenciou um momento de crise (Basaglia, 1985).

Se as oficinas terapêuticas se basearem na primeira forma de atuação, os usuários serão habilitados a praticar alguma atividade; no entanto, as oficinas estarão restritas apenas a esse objetivo. Dessa forma, com a preocupação de apenas tornar os participantes aptos a um determinado trabalho, em uma determinada instituição de tratamento, produz-se uma adaptação dos usuários a essa instituição e procura-se que eles sejam comportados para o perfeito funcionamento daquela "casinha de loucos". Assim, constrói-se o que Fadista e Araújo (2004) chamaram de paralelismo social, o que mantém aqueles que possuem transtornos mentais exilados do lado de fora do manicômio.

Já em Trieste, buscava-se que o trabalho artístico fosse como o proposto pela segunda maneira descrita anteriormente, ou seja, estendendo a ação para o território. Lima (2004) comenta que, nessa cidade italiana, os denominados "laboratórios" localizavam-se no exterior das instituições de saúde mental e eram espaços de criação em que não havia apenas a participação dos usuários de saúde mental, mas também da comunidade. Os trabalhos produzidos nesses laboratórios eram expostos em diversos locais da cidade e interferiam na paisagem e no universo cultural de seus habitantes. Com isso, buscava-se a integração e convívio com a população da cidade e a valorização das produções dos participantes dos "laboratórios" pela sociedade, contribuindo, assim, para uma ruptura do estigma do louco.

No Brasil, há oficinas terapêuticas que também pretendem romper com esse estigma e, consequentemente, promover a desinstitucionalização. Através de atividades artísticas fora do âmbito estritamente institucional, permite-se que aqueles que vivenciaram a experiência de crise transitem pela cidade, usufruam do patrimônio artístico-cultural, descubram novos lugares significativos e novos interesses. Busca-se, dessa maneira, a democratização de espaços. Espaços onde é possível sair do lugar de impotência e passividade e buscar posições ativas, de protagonismo e de produção cultural. Essas ferramentas inclusoras são fundamentais para as oficinas terapêuticas, já que qualquer atividade ou "instituição que agrupe doentes mentais, tende a cronificar-se" (Lancetti, 2006, p. 46).

Um importante instrumento para a inclusão social é o que Roberto Tykanori Kinoshita (1996) chama de poder contratual. O poder contratual é um valor previamente atribuído para cada indivíduo dentro do campo social, o qual possibilita relações de troca. São componentes desse valor 
as trocas de bens, de mensagens e de afetos. Os chamados doentes mentais são considerados pela sociedade com um valor de poder de contrato negativo, já que os bens dos loucos tornam-se suspeitos, as mensagens incompreensíveis e os afetos desnaturados.

Segundo Kinoshita (1996), para que se aumente o poder contratual, é preciso reconstruir esses valores e promover a reabilitação psicossocial. "Reabilitar pode ser entendido como um processo de restituição de poder contratual do usuário, com vistas a ampliar a sua autonomia" (p. 56).

Kinoshita propõe, ainda, uma discussão interessante sobre autonomia, ao dizer que não se deve confundir esse termo com autossuficiência e com independência, pois dependentes todos somos. Ele diz que a questão daqueles que possuem transtornos mentais em relação à dependência é de quantidade. São muito dependentes de poucas relações/coisas e, por isso, pouco autônomos."Somos mais autônomos quanto mais dependentes de tantas mais coisas pudermos ser, pois isso amplia as nossas possibilidades de estabelecer novas formas, novos ordenamentos para a vida" (Kinoshita, 1996, p. 57).

Com as atividades expressivas, pretende-se promover a autonomia e aumentar o poder contratual dos indivíduos. Ao possibilitar a circulação dos usuários nos diversos territórios e agenciar formas de eles se relacionarem com um número significativo de pessoas - não outros indivíduos que são excluídos, mas também aqueles que se interessam em experimentar a arte - produz-se uma dependência de uma maior possibilidade relações e os usuários de saúde mental deixam de ser considerados suspeitos, incompreensíveis e sem afetos. Ou seja, ocorre uma desmistificação da loucura.

É, porém, fundamental que essa desmistificação aconteça não só em relação à comunidade que participa das atividades, mas a toda a população. Com as oficinas, é possível que a sociedade atente para os trabalhos daqueles que possuem transtornos mentais, valorize-os e perceba que é plenamente possível o convívio com a diferença.

Assim, através da arte, os sujeitos que vivenciaram a experiência da loucura constroem novos vínculos e relações com o circuito social e incluem-se no mundo da cidadania. Amplia-se, portanto, seu universo de relações, sua circulação social e desenvolvem-se alternativas para a inserção de singularidades na sociedade (Lima, 2004).

\section{Considerações Finais}

Diferentemente das antigas formas de assistência aos sujeitos que vivenciaram momentos de crise psíquica, as oficinas terapêuticas expressivas buscam uma ruptura com a segregação e com a mera adaptação dos usuários de saúde mental a uma sociedade alienante e adoecedora. Tais procedimentos pretendem desconstruir a maneira como o trabalho era utilizado no tratamento moral dos chamados doentes mentais, o qual pro- 
punha torná-los aptos a executar um serviço mecânico para a manutenção da instituição de "tratamento". Além disso, propõem romper com o enquadramento dos sujeitos em diagnósticos que apenas consideram a sintomatologia apresentada. Portanto, as oficinas são um dos instrumentos da Reforma Psiquiátrica por ser uma força contrária à lógica manicomial que ainda está presente em muitas instituições.

Essas atividades visam à possibilidade de convivência das múltiplas singularidades, através de diversas formas de expressão - seja corporal, auditiva ou verbal - em espaços comunitários, não se restringindo aos serviços de saúde mental. O que se pretende é a circulação de palavras, de afetos, de produções artísticas nos diversos territórios para que haja, assim, uma transformação de como a sociedade enxerga o louco e se promova a desinstitucionalização. Ao permitir experimentações no campo da arte e da cidadania, possibilita-se o transbordamento de sensações e sentimentos por outras vias e a produção de novas subjetividades. Produzem-se saídas para a estigmatização e a exclusão e incluem-se aqueles que divergem da serialização de subjetividades.

Contudo, quando se considera uma única forma de se trabalhar com saúde mental como uma verdade absoluta e ideal e não se abrem possibilidades de problematizações, corre-se o risco de propor mais um tratamento cristalizado e cronificante. É fundamental que haja uma constante reflexão crítica do trabalho que está sendo realizado para evitar que se caia nas armadilhas da psiquiatria segregadora e da sociedade de controle. Portanto, é preciso um incessante espírito de inovação para que o movimento da Reforma Psiquiátrica possa ultrapassar as barreiras resistentes.

\title{
Expressive ateliers: an inclusion of singularities
}

\begin{abstract}
This article intends to make a critical reflection on the artistic activities accomplished in mental health services, and in many social spaces. Initially, it's contextualized how mental illness has been perceived in society, how the work seemed to be a moral treatment, and how the psychiatric assistance has been modified through history. Following, we consider the still excludent forms of accomplishing therapeutical workshops only in services of mental health, and with the exclusive participation of people with mental disturbances. The traditional and chronifying clinical practice is also questioned. Another discussion is about the segregation of people who deviate from the serialization of subjectivities imposed by a society of control. Expressive activities consider the inclusion of multiple singularities. Moreover, there is a search for a way of sheltering the multiple forms of language, not only those restricted to the verbal one, and the circulation of affection and artistic productions in different communitarian territories.
\end{abstract}

Keywords: Mental health. Artistic experimentations. Production of subjectivities. Social insertion. 


\section{Ateliers expressifs: une inclusion des singularités}

Résumé : Cet article vise à faire une réflexion critique sur les activités artistiques réalisées dans les services de santé mentale et dans divers espaces sociaux. Initialement, on contextualize comme la folie a été perçue socialement, comme le travail a été vu sous la forme de traitement moral et comme l'assistance psychiatrique s'est modifiée pendant l'histoire. À suivre, on pose quéstion sur les formes d'ateliers thérapeutiques qui encore excluent les personnes, dans la mesure où ils sont realisés seulement dans services de santé mentale et seulement avec la participation de personnes qui souffrent de bouleversements mentaux. On discute aussi la clinique traditionnelle et chronifiée et la ségrégation des personnes qui dévient de la serialization de la subjectivité imposée par la société de contrôle. Les activités expressives proposent l'inclusion de multiples singularités. En outre, on cherche accueillir les diverses formes de langage - non seulement celles-là restreintes au verbal - et permettre la circulation d'affections et de productions artistiques dans divers territoires communautaires.

Mots clés: Santé mentale. Expérimentations artistiques. Production de subjectivité. Insertion sociale.

\section{Oficinas expresivas: una inclusión de singularidades}

Resumen: Este articulo pretende hacer una reflexión sobre las actividades artísticas realizadas en los servicios de salud mental y en los diversos espacios sociales. Inicialmente, se contextualiza como la locura ha sido percibida socialmente, como el trabajo en la forma de tratamiento moral y como la asistencia psiquiátrica se ha modificado en el recorrer de la historia. A seguir se problematizan las formas todavía exclusoras de realizar oficinas terapéuticas solo en servicios de salud mental y solamente con la participación de personas que tienen trastornos mentales. Se cuestiona, aún, la clínica tradicional y cronificante. Se discute, todavía, la segregación de los que desvían de la socialización de subjetividades impuestas por la sociedad de control. Las actividades expresivas proponen la inclusión de múltiples singularidades. Fuera de eso, se busca un acogimiento a las diversas formas de lenguaje, no solo aquellas restrictas al verbal, pero también a la circulación de afectos y producciones artísticas en diversos territorios comunitarios.

Palabras clave: Salud mental. Experimentaciones artísticas. Producción de subjetividades. Inserción social. 


\section{Referências}

Almeida, A. M. G., Moraes, B. M., Barroso, C. M. C., Barros, M. M. M., \& Sampaio, J. J. C. (2004). Oficinas em saúde mental: relato de experiências em Quixadá e Sobral. In C. M. Costa \& A. C. Figueiredo (Orgs.), Oficinas terapêuticas em saúde mental: sujeito, produção e cidadania (pp. 117-133). Rio de Janeiro: Contra-Capa.

Amarante, P. (1995). Loucos pela vida. Rio de Janeiro: Fiocruz.

Amarante, P. (2003). A (clínica) e a reforma psiquiátrica. In P. Amarante (Org.), Archivos de saúde mental e atenção psicossocial (pp. 45-65). Rio de Janeiro: NAU.

Basaglia, F. (1979). A psiquiatria alternativa. São Paulo: Brasil Debates.

Basaglia, F. (1985). A instituição negada. Rio de Janeiro: Graal.

Bezerra, B. (2004). O cuidado nos Caps: os novos desafios. Academus - Revista Científica da SMS Rio de Janeiro, 3(4). Recuperado em novembro de 2007, de http://www. saude.rio.rj.gov.br/saude/pubsms/media/cuidado_nos_caps.pdf

Brasil. Ministério da Saúde. Secretaria Nacional de Assistência à Saúde (1991). Portaria $n^{\circ} 189$ de 19 de novembro de 1991. Recuperado em outubro, 2007, de www.inverso. org.br/index.php/content/view/6887.html

Brasil. Ministério da Saúde. (2001). Lei n 10.216, de 6 de abril de 2001. Recuperado em novembro de 2007, de www.planalto.gov.br/CCIVIL/LEIS/LEIS_2001/L10216.htm.

Brasil. Ministério da Saúde. (2004). Saúdemental no SUS: Os Centros de Atenção Psicossocial. Recuperado em setembro de 2007, de LILACS (Latin American and Caribbean Health Sciences): www.inverso.org.br/index.php/content/view/12211.html

Brasil. Ministério da Saúde. Secretaria de Atenção à Saúde. Departamento de Ações Programáticas Estratégicas. Coordenação Geral de Saúde Mental. (2005). Reforma psiquiátrica e política de saúde mental no Brasil - Documento apresentado à Conferência Regional de Reforma dos Serviços de Saúde Mental: 15 anos depois de Caracas. Recuperado em novembro de 2007, de http://www.rio.rj.gov.br/fjg/ publique/media/Relatorio_quinze_vinte_anos_Caracas.pdf

Cedraz, A., \& Dimenstein, M. (2005). Oficinas terapêuticas no cenário da Reforma Psiquiátrica: modalidades desinstitucionalizantes ou não? Revista Mal-Estar e Subjetividade, 5(2), 300-327. Recuperado em agosto de 2007, de http://redalyc. uaemex.mx/redalyc/pdf/271/27150206.pdf 
Coimbra, C. M. B. (2001, janeiro/abril). Mídia e produção de modos de existência. Psicologia: Teoria e Pesquisa, 17(1), 1-4. Recuperado em novembro de 2007, da SciELO (Scientific Electronic Library Online): www.scielo.br

Corbisier, C. (2000). A reforma psiquiátrica: avanços e limites de uma experiência. In P. Amarante (Org.), Ensaios, subjetividade, saúde mental, sociedade (pp. 279-299). Rio de Janeiro: Fiocruz.

Fadista, M., \& Araújo, M. S. (2004). Arte, horta \& Cia: trabalho protegido no CAPS Arthur Bispo do Rosário. In C. M. Costa \& A. C. Figueiredo (Orgs.), Oficinas terapêuticas em saúde mental: sujeito, produção e cidadania (pp. 135-147). Rio de Janeiro: Contra-Capa.

Fonseca, T. M. G. (2005, janeiro/junho). Imagens que não agüentam mais. Episteme, 20, 101-110. Recuperado em novembro de 2007, de http://www.ilea.ufrgs.br/ episteme/portal/pdf/numero20/episteme20_artigo_fonseca.pdf

Foucault, M. (1995). História da loucura. São Paulo: Perspectiva.

Goldberg, J. I. (1992). A doença mental e as Intituições - a perspectiva de novas práticas. Dissertação de Mestrado, Faculdade de Medicina, Universidade de São Paulo, São Paulo.

Guerra, A. M. C. (2004). Oficinas de saúde mental: percurso de uma história, fundamentos de uma prática. In C. M. Costa \& A. C. Figueiredo (Orgs.), Oficinas terapêuticas em saúde mental: sujeito, produção e cidadania (pp. 23-58). Rio de Janeiro: Contra-Capa.

Kinoshita, R. T. (1996). Contratualidade e reabilitação psicossocial. In A. Pitta (Org.), Reabilitação psicossocial no Brasil (pp. 55-59). São Paulo: Hucitec.

Lancetti, A. (2006). Clínica peripatética. São Paulo: Hucitec. (Coleção Saúdeloucura, 20)

Lima, E. A. (2004). Oficinas e outros dispositivos para uma clínica atravessada pela criação. In C. M. Costa \& A. C. Figueiredo (Orgs.), Oficinas terapêuticas em saúde mental: sujeito, produção e cidadania (pp. 59-81). Rio de Janeiro: Contra-Capa.

Mangia, E. F. (1997, maio/dezembro). Psiquiatria e tratamento moral: o trabalho como ilusão de liberdade. Revista de Terapia Ocupacional da Universidade de São Paulo, $8(2 / 3), 91-97$.

Mendonça, T. C. P. (2005, dezembro). As oficinas de saúde mental: relato de uma experiência de internação. Psicologia: Ciência e Profissão, 25(4), 626-635. Recuperado em outubro de 2007, da SciELO (Scientific Electronic Library Online): www.scielo.br 
Oliveira, J. A. M. (2006). O processo de desinstitucionalização da loucura em serviços de saúde mental no estado de Sergipe: um problema clínico-político. Dissertação de Mestrado, Universidade Federal Fluminense, Niterói, RJ.

Rauter, C. (1997). Subjetividade, arte \& clínica. In A. Lancetti (Org.), Saúdeloucura (Vol. 6, pp. 109-119). São Paulo: Hucitec.

Rauter, C. (2000). Oficinas pra que? Uma proposta ético-estético-política para oficinas terapêuticas. In P. Amarante (Org.), Ensaios, subjetividade, saúde mental, sociedade (pp. 267-277). Rio de Janeiro: Fiocruz.

Rocha, A. (1997). Experiência da toca. In A. Lancetti (Org.), Saúdeloucura (Vol. 6, pp. 135-142). São Paulo: Hucitec.

Valladares, A. C. A., Lappann-Botti, N. C., Mello, R., Kantorski, L. P., \& Scatena, M. C. M. (2003). Reabilitação psicossocial através das oficinas terapêuticas e/ou cooperativas sociais. Revista Eletrônica de Enfermagem, 5(1), 4-9. Recuperado em agosto de 2007, de www.fen.ufg.br/Revista

Varella, A. (1997). Lygia Clark: arte e terapia. In A. Lancetti (Org.), Saúdeloucura (Vol. 6, pp. 120-122). São Paulo: Hucitec.

Flávia Helena Passos Pádua, Aprimoranda do Instituto de Saúde/SES - São Paulo. Rua Prudente de Morais, 1170, apto 104. CEP: 14015-100. Ribeirão Preto, SP. Endereço eletrônico: flaviapadua@yahoo.com.br

Maria de Lima Salum e Morais, Pesquisadora científica do Instituto de Saúde/SES São Paulo. Rua Novo Cancioneiro, 75, apto.31, Jardim das Acácias. CEP:04704-080. São Paulo, SP. Endereço eletrônico: salum@isaude.sp.gov.br

Recebido em: 8/12/2008

Aceito em: 9/07/2009 